\section{ORIGITAL COMMUNTCATIONS.}

\section{ILLUSTRATIONS OF TUBERCLE.}

By EDWARD HENRY SIEVEKING, M.D., Fellow of the Royal College of Physicians, Assistant Physician to St. Mary's Hospital, etc.

(Read before the Harvian Society of London, April zth, 1853.)*

THs term tubercle is synonymous, as we all know, with nodule, and does not in itself imply any peculiar constituents. Usage has, however, limited the application of the denomination to a certain form of deposit, which we meet with but too frequently in the cadaveric inspections which with are allowed to make, and which, at all ages of life, is a source of danger to the individual, and of serious considersource of danger to the medical practitioner. There is no necessity for urging the importance of the subject; but it is sometimes useful to bring a familiar fact before our eyes in a form in which we are not in the habit of seeing it. Thus, we find, with regard to the frequency of tubercular disease, by striking an average of ten weeks taken at random in the Registrar-General's Report for 1851, that it ranks second in mortality of all the causes which the returns specify. $\mathbf{Z y -}$ motic diseases stand first; tubercular maladies follow in their wake; diseases of the lungs and of the brain respectively occupy the third and fourth position. The exact numbers for the ten weeks are as follows:-

$\begin{array}{cccc}\text { Mortality from zymotic diseases, } & 19,914 \\ " & \# \text { tubercular diseases, } & 18,395 \\ " & \Rightarrow & \text { cerebral diseases, } & 12,068 \\ " & \Rightarrow & \text { pulmonary diseases, } & 15,475\end{array}$

But we all know that individuals are frequently carried off by diseases to which a name is applied that does not indicate any tubercular affection; while the scalpel exhibits to us lesions sufficiently indicative of tubercle having been sown, or of such a taint having existed in the circulating fluid as to produce that peculiar debilitating effect which renders treatment ineffectual, which, under more favourable circumstances, might have saved the patient. So far, then, from diminishing the Registrar-General's ratio, or rather the ratio indicated by his figures, we would enforce the earnest lesson they teach still further, by pointing to the numerous cases included under other headings, which, though not bearing the stamp of tubercle so prominently, yet do present it, and therefore deserve to be classed with the second department.

That constitutional tendency which leads to the deposit of tubercle, and is to be found wherever the necessary stimuli of life, and, abore all, pure atmospheric air, are deficient, predisposes to other diseases as well; it assists the approaches of the enemy, and actually places the fortress in his power before a formal assault is made. Though we no longer believe in the elements of Thales, we may, without a great stretch of the laws of the natural sciences, admit that air is the chief element of health or disease, according as it is supplied to the lungs in its unadulterated condition of four-fifths nitrogen and one-fifth oxygen, or as it carries diffused through it carbonic acid gas, carbonetted hydrogen, sulphuretted hydrogen, the effluvia of cesspools and drains, the poison of influenza or cholera, the emanations of the variolous or typhous patient. As long as it was supposed possible that the royal hand could charm away by its mere touch the accumulated effects of long neglect of Divine laws, and crowds of scrofulous subjects thronged the path of royalty in order to be saved from their loathsome disease, neither could the patient be relieved, nor the dignity of the healing art be vindicated. But, though the darkness that spread over the human mind has been somewhat lightened, and though we may have penetrated be-

- The paper was accompanied by a large number of illustrative drawings, which we are necessarily precluded from giving the readers of the Asof which we are necessarily precluded from giving the readers of the Asmeaning. yond the first barriers of knowledge, so as to obtain a glimmer of the goal for which we have to struggle, we are jet far from having reduced the various forms of diseased action to such definite laws that we may arrange them as a science, and rest contented with the contemplation of the edifice which our predecessors and our contemporaries have erected. There is much which we may yet learn from the fathers of medicine, in regard to the patient and careful analysis of disease; but we possess this undoubted adrantage orer them, that, in the means of analysis, in the aid afforded by chemistry and the microscope, we may approach nearer to the elements of vital action, whether in its normal or in its perverted state, than they were able to do. Still, even here we must not blind ourselves to the fact, that we have scarcely reached beyond the elements, not of diseased action, but of the products of diseased action; and not even have we succeeded in displaying the primary effects of morbid action, but all we can assert as having been achieved is the investigation of its secondary products. Hewson and Gulliver, Christison, Bright, Andral, Frerichs, Garrod, and many others whose names are familiar to you by their researches into the constitution of the blood in disease, have earnestly laboured to grasp their primary effects. Their light shines on our path, and will illumine the tottering steps of future inquirers ; but beyond a faint indication of what is to be done, we can scarcely admit a great approach to what lies before us; and we are perhaps constrained to admit that we shall not understand the relation of secondary effects until we have a greater insight into the first changes constituting disease. Yet we have no alternative but to proceed rigidly in our analytical inquiry, holding strictly to the legitimate mode of research, and eschewing all hypothesis for which we have not the guarantee of scientific induction.

The questions which suggest themselves for solution, in regard to any morbid growth, apply equally to the subject of tubcrcle. They affect the origin, the mode and situation, and the ultimate constituents and character, of the deposit. Each of these involves subjects for further consideration, not the least of which is the medical treatment. It is, however, manifest, that, until we have a definite understanding of the points first alluded to, our therapeutic proceedings will be conducted in the dark. They may be occasionally successful, but they will be altogether empirical; and we shall derive little intellectual profit or gratification from our profession. A knowledge of the precise locality in which tubercle is deposited will necessarily aid us in determining whether and how we can attack it locally ; a correct appreciation of its ultimate elements will enable us to choose the remedies which may affect the product, or diminish the constitutional tendency in the most secure and legitimate manner. If our studies show us that in many instances the product of the tubercular cachexia is beyond the reach of curative agents, we may at least hope to discover the laws regulating its introduction into the system, an acquaintance with which will enable us to avoid those causes which induce the constitutional taint.

Allow me, then, briefly to advert to the origin of tubercle. We possess sufficient evidence to show that it is derived from the blood; that it transudes from the capillary vessels of the part in which we find it; and that, after having been deposited, it is liable to undergo certain further changes. On a close examination of incipient tubercular deposit, we may always note that there is congestion in the tissues immediately surrounding it. In the pia mater of the Sylvian fissure, we see an increased redness, in which a few vessels are more prominent than usual; in the pulmonary parenchyma we may, especially by the use of the microscope, discover the engorgement of the interlobular capillaries investing the uir vesicle into which the tubercle is being secreted; in the mucous membrane of the intestines, we see the exquisite arborescent arrangement of the congested vessels, tending from the mesenteric attachment to the point where we observe the deposit shining through the mucous surface from the submucous tissue, in which it has collected. The first elimination of the morbid 
product acts like a magnetic point of attraction, and generally serves as a centre round which the deposit progressively enlarges by eccentric deposition. The amount of vascular action accompanying the elimination varies in different individuals ; in some, there is scarcely a perceptible increase in the sanguineous current; in others, we cannot deuy the presence of acute inflammation, shown both by the congested state of the blood-vessels, and by the presence of plastic exudation and exudation corpuscles. In ordinary inflammatory conditions, we may actually observe the part taken by the capillary vessels in the process of transudation. We see the inflammatory product immediately after its passage through the vascular membrane, coating the ressels; and, if my limited observations justify the statement, we may see the same matter within the vessels, adhering to the coats, previous to its discharge. Whether it be so or not, whether we may be enabled to observe the transition of the contents of the vessels into the surrounding parts or not, it is evident that we ought not to be satisfied with ascertaining the fact of the exudation as the primary change: we are driven to take one step more, before we gain the fountain-head of the malady ; we therefore look to the constitution of the blood itself in tubercular disease, in order to ascertain whether any deficiency in the normal components, any variation in their relative amount, any new products, are to be met with, which may explain the source of the extravascular deposit. All observers, who have brought either the microscope or chemical analysis to bear on this subject, are agreed that there is an alteration in the blood, indicating a want of vigour and tone. There is a general increase in the fluid parts, the water and albuminous constituents; while the solids are diminished, the fibrine and the red corpuscles are reduced in quantity, and both exhibit what has been termed a diminished vitality; the fibrine possesses less plasticity ; the blood corpuscles are feebly formed, their outline less defined, their colour faint, and the colouring matter easily yielded up to the surrounding fluid. The actual relation of the white cell to the red corpuscle in various diseases has not as yet been satisfactorily demonstrated; but we are inclined to view an excessive development of the former as indicative of debility, and an aplastic, if not cacoplastic, condition of the blood: we certainly have noted an increase in their number in persons affected with tubercle. Many of the peculiarities in the blood of tuberculous individuals are also met with in the blood of individuals labouring under other diseases. We are not, therefore, justified in laying down any absolute indications which are conclusive evidence of the tubercular infection; and if we are unable to define the specific constitution of the blood that accompanies tuberculosis, it follows, a fortiori, that we are not possessed of the means of predicating a mere tendency to tubercular deposit from the constitution of the blool. This, however, is the point at which we must hope to arrive, if, as we believe, one of the primary elements of the malady is traceable to the blood, and the seeds of the disease are sown, and nust therefore be destroyed here, unless they be anticipated before their introduction into the body. On this point, Mr. Ancell, in his laborious work on "Tuberculosis", judiciously remarks :"The predisposition differs from the general disease only in degree, and the condition of the blood in the predisposition is the same, differing only in degree"; and so undoubtedly it is, but we yet want that positive and conclusive sign by which the predisposition may be recognized by analysis of the blood. It is manifest that, with regard to tuberculosis as well as other diseases, such an indication would be of extreme value; for, as the diagnosis of morbid processes in the thorax has improved, our treatment of these diseases has commensurately acquired greater simplicity and greater certainty. In the same way, it is tolerably certain that, if we discovered the means of recognizing the seeds of a malady before they had taken firm hold upon the system, we should be enabled to eradicate them, or to counteract their influence more effectively than we now can.

It is not my object at present to examine all the dietetic and regiminal circumstances which are daily forced upon our notice in connexion with tubercular diecese ; but I must advert to one point bearing upon the question of its origin, before proceeding to the second division of the subject. It refers to the organ by which the malady is introduced into the system. Are we to lay the chief fault to the perspiratory apparatus of the surface, to the organ of oxygenation and purification, or to the digestive and blood-making apparatus ? I need not point out to you how each of these affect the constitution of the blood by overcharging it, positively or negatively ; that is, by conveying into it material in excess, or by allowing material to accumulate which ought to be eliminated from the system. Formerly, the corpus delicti was invariably the stomach; now, popular prejudice is directed chiefly against the lungs: and, though I am not desirous to deprive the former of its just claims to power and influence, I confess myself to be one of those who attribute in the production of the tubercular disease a greater share to the organs of oxygenation than to those of sanguification. Baudelocque, who has written some of the wisest remarks on the relation between the respiratory function and tuberculosis that I have met with, affords some rery striking illustrations of this position. He states as the result of his examinations and experience, that a truly scrofulous disease is invariably caused by vitiated air, and that it is not always necessary that there should have been a prolonged stay in such an atmosphere. Often a few hours each day may suffice, and it is thus that patients may live in the most healthy country, pass the greater part of the day in the open air and yet become scrofulous, because they sleep in a confined place where the atmosphere has not been renewed. M. Baudelocque illustrates these observations by numerous well chosen instances; he refers, among others to the shepherds of his country, who may become scrofulous although they lead an open air life; but although, as he says, the disease with them is attributed to exposure to storms, to atmospheric vicissitudes, and to humidity, attention has not been paid to the circumstance that they pass the night in a confincd hut, which they transport from place to place, and which protects them from the rain; this hut has only a small door which is closed when they enter, and also remains closed during the day; six or eight hours passed daily in vitiated air, which is never renewed, is the true cause of their malady. I have spoken of the bad habit of sleeping with the head under the clothes, and the insalubrity of schoolrooms, in which a number of children are assembled together. The repetition of these circumstances is often a sufficient cause of scrofula, though they may last but for a few hours a day. Human beings and animals are equally affected by vitiated air: close rooms, as Dr. Arnott has pithily remarked, act like extinguishers to the vital flame; and the extinction literally takes place at the point at which the fuel accumulates for want of being burnt off. If space and time allowed, I would multiply the evidence that has been adduced in support of the particular view which I have dilated upon; but this is beyond the limits of this paper, and morecver, there is now scarcely a necessity for enforcing what, I believe, is the prevailing opinion among medical men. To sum up, while we would not deny which defective supply of food and raiment influences the production of tubercular disease, no cause so certainly predisposes to and generates it as defective aeration. The exact part taken by the light in this matter cannot be appreciated. Its direct influence upon the health of everything living is proved irrefragably ; but whether its absence can alone induce morbid states of a definite character, romains yet to be proved.

As the tubercular deposit is derived from the blood, it is not surprising that all the organs of the body are more or less liable to become the seat of the morbid product. Some tissues present a greater proclivity to the elimination than others; and some, as the fibrous and tegumentary tissues, appear to enjoy almost an immunity from tubercle. At the two ends of the scale, we may place the mucous membranes and the fibrous tissues: the former are the true soil for this tree of death ; the latter are rarely, if ever, affected. There can be little doubt that this depends in a measure upon 
certain physical laws, influencing the current in the rascular syatem, and determining the greater or less facility of transudation, in the first instance. I should venture to suggest, that we may lay it down as a law regulating the doposit of tubercle, that it is effected at that point of an organ or of a tissue where the smallest amount of pressure is exerted upon the capillary system. This does not exclude the operation of other laws, which determine the attraction to any one organ. It does not offer any reason why in one case we find tubercle in the spleen, in another in the mesenteric or bronchial glands, in a third exclusively in the pulmonary tissues; but it seems to embrace the various circumstances modifying the exact site of the deposit in these different parts of the system. The vis a tergo varies but little in the different parts of the capillary system; but the relation to surrounding tissues differs very much. Thus, while the force with which the blood is driven into the nutrient artery of the sternum, and into the interlobular plexuses of the lungs, is identical, the pressure which the respective capillary systems meet with in a case of congestion, which implies a tendency to exudation, is necessarily greater in the bone than in the soft parenchymutous structure. No organ is more frequently the seat of tubercular deposit than the lungs, and in none do we find the capillary ramifications of the vessels with so little covering. They almost lie naked on the surface. Beyond the basement membrane forming the air vesicles, and possibly a delicate epithelial layer, there is nothing between the capillary network and the atmosphere. We need not therefore wonder that the ultimate resicle in which the bronchule terminates is, above all other points, that of tubercular election. The receptacle is ready; the product being in the blood, a slight increase of pressure will overbalance the natural and healthy equilibrium between the external and the internal fluids, and the discharge takes place. If our view is correct, nothing but a previous change in the ultimate resicles or bronchules could give rise to a deposit of tubercular matter in the intervesicular tissue, in the parenchyma of the lung itself, as contradistinguished from the respiratory cavities. We can suppose that obliteration of a portion of the breathing apparatus might leave the intervesicular texture less resistent than the air vesicles; and in that case we should expect to find an interstitial deposit. Whether this does actually occur I am not prepared to say. I have not seen any appearances that would justify the assumption of a primary interstitial deposit, but I have seen a distinct doposit of tubercular matter within the air-vesicles, and I have traced its primary deposit, in the semi-liquid form, in the solitary vesicle, to the deposit in numerous adjoining vessels, causing destruction of their breathing power and obliteration of the bronchule terminating in them. There is some difficulty connected with these investigations, which I may point out to those members who are not in the constant habit of employing the microscope. The air-bubbles issuing from the pulmonary tissues that have not been entirely obliterated, are very liable to obscure the field of vision, and to prevent our observations; while, when the entire obliteration by which all air is expelled has taken place, the parts are rendered so opaque, that it is next to impossible to obtain sufficiently delicate sections to show the specimens clearly. It is only by frequent examinations, and by carefully watching our opportunities, that we can succeed in obtaining well defined specimens. I may take this opportunity of remarking, that in the drawings I have added nothing from my imagination. They are as accurate representations of nature as my abilities allowed me to give ; but as they were all taken with the object before me, whether viewed with the naked eye or with the microscope, I pledge myself for their truthfulness, 80 far as I can answer for my eye and my hand.

Before proceeding, I may be allowed to advert to the drawings, so far as they illustrate the remarks which I have hitherto ventured to offer to you. The most marked evidence of the congestion surrounding recent tubercular deposit is given in drawing $15 \mathrm{c}$ (Fig. 1). The blood being more persistent in the vessels than in a healthy lung, I

succeeded in obtrining distinct views of the loops encircling, as you will perceive, the ultimate air-vesicles. I next refer you to figure No. 91a (Fig. 2), to show how the
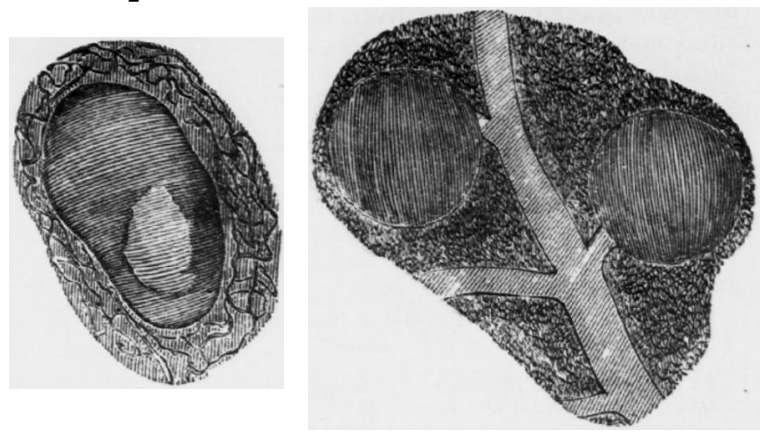

Fig. 1. A single miliary tubercle, semiopaque, surrounded by highly injectod blood-ressels. Mag. 211 diameter.

Fig. 2. Semioparue miliary tuberele, deposited throughout both lungs of a child, aged 5 years, a patient of Dr. Markhan's. "The tuberuular matter distends the nltimate air-vesicle, the basement membrane of which is clearly detined. The ultimate bronchule is perfectly free and patulona. The tubercular matter fills tho vesicle as a bullet tilis its mould. Mag.

eff usion of tubercular matter takes place into the ultimate air-vesicle, causing it in the first instance to assume a globu lar form, and entirely impeding any interchange between

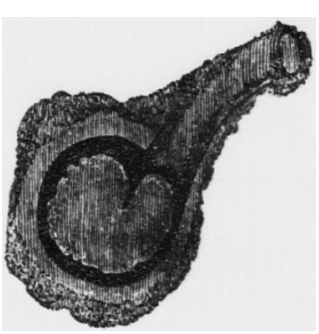
the atmosphere and the terminal loops of the pulmonary artery. In the drawing alluded to, as in one or two others taken from tubercular lungs, you will perceive that the deposit is surrounded by a dark ring when a low power is used, which, under a high power, proves to be a circle of exudation corpuscles. (Figs. 3 and 4.) Wherever this is observed, Fig. 3. Nerent milinry tubercle, also We know, if any further deshowing the deposit within the ulti. We knowation bejond the naked leading to it, the latter as yet patu- eye view is required, that lous. The tubercular untter is sur. eye view is required, that tion corpuscles. From a man aged proceeding. Not that inflam(ii), a patient of Dr. T. K. Chambers, procen is never seen without
who had been ill six wecks. Jrag. mation is 40 dinmeters. this corpuscular exudation, but that its presence is now considered certain proof of an

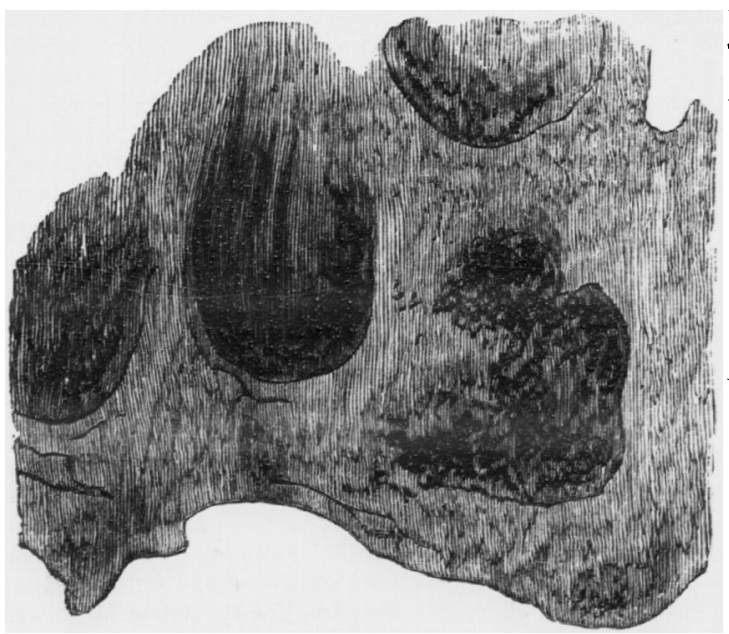

Fig. 4. Grey miliary tubercle, to show the limitation of the deposit within the air-vesicles and the exudation surrounding the former. From a patieut of Dr. Sieveking, a man aged 27. There whs extensive tubercular deposit represented in the cut. 
inflammatory process. I may remark parenthetically, that while we rarely, if ever, meet with an inflammatory condition of the lungs and brain, in which this microscopic sign is absent, it much more rarely occurs in other organs and tissues, as in the kidneys or liver, in the pericardium or abdominal mucous or serous coats. Drawing No. 25 (Fig.5) affords

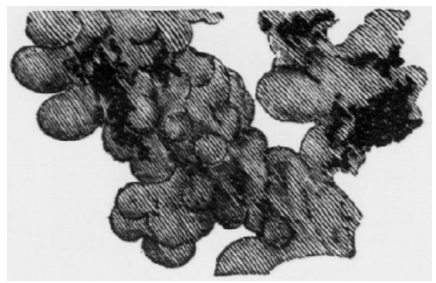

Fig. 5 shows the more advanced stage of tubercular deposit. The air-vesicles are closcly aggregated together, but the pressure is nut yet sufticient to destroy their general circular form. Sinne melanotic mutter is seen scatcered upon them. Truken from a female patient of Dr. Weber's. Mag. (i) dian.

another instance, on a larger scale, of the deposit of tubercle within the respiratory cavities. Here, too, the deposit scarcely having consolidated, the pressure has not affected these vesicles universally in such a manner as to cause the circular outline to be destroyed. Of this effect of increased pressure, No.32 (Fig.6) affordsdemonstrative proof. Here you

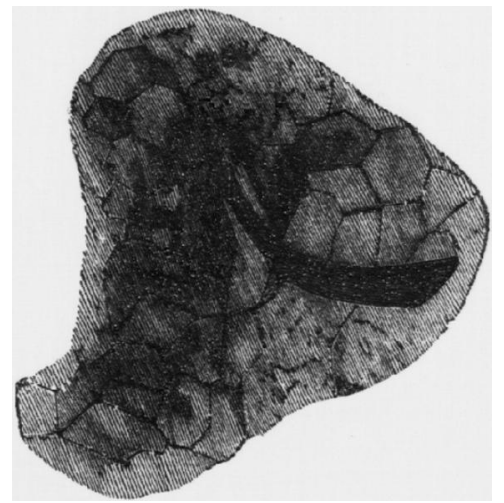

Fig. 6. Crude yellow tubercle; the circular forn of the resicles is destroyed by the mutual pressure exerted in consequence of the advance of the deposit; the bronchule lendinir to the clustel is obliterated, and converted into a mere ligumentous band. Mag. 80 diam. The specimen is taken from a putient of Dr. Markhau's.

observe the vesicles presenting a honeycombed appearance, with an almost uniformly hexagonal outline, in perfect accordance with the physical laws which you are familiar with. The bronchule, you perceive, leading to this obliterated portion of lung-tissue, is in each instance equally rendered impervious, and the tubule that ought to be patulous, to permit the passage of the vivifying stimulus of air, is choked up, fine-drawn, converted into a blind alley. Observe, too, in this case, the utter obliteration of the interstitial tissue, which, in No.91 (Figs. 2,3), is seen to intervene between the vesicles containing the tubercular matter. These illustrations offer nothing new, and nothing unexpected; and yet we seem to feel a surprise that a disease should produce so palpable and mechanical a change in the most vital organs, and that our means to arrest and destroy it should amount as yet to so very little.

The law to which we have adverted as, in our opinion, regulating the depsit of tubercle, viz., that the tendency to the deposit in any organ is inversely as the pressure the vessels sustain, or that it is in the ratio of the laxity of the tissues, is supported by the views which are commonly held with regard to the chemical constitution of tubercle, by the form and mode of deposit in the various organs of the body, and it also assists us in explaining why certain parts of different organs possess so marked a liability to become the seat of tubercular exudation. This feature constitutes an essential difference betreen tubercle as a mere effusion of artain constituent of the blood, and those other new formations in which we cannot but $80 e$ a tendency to indopendent development or organisation. The most familiar instance of pathological processes with which I would compare it, are the serous effusions that take place into the peritoneal cavity, from obstruction to the rens cava or portal system, inducing congestion and consequent liquid discharge at the most yielding points. If we adopt the view suggested, it appears to me to offer an explanation of the circumstance that the apices of both lungs are the chief seats of tubercle, while it tends to show the importance of encouraging the use of all the physical means at our command to promote a free and active circulation of the entire vascular current, and to obviate and anticipate anything approaching to local congestion in the organs and parts of organs which we know to be most liable, at different periods of life, and under different circumstances, to become affected with the disease in question. The manner in which I would apply the law to the explanation of the predominant proclivity of the pulmonary apices, is simply this : the upper portions of both lungs are surrounded by more unyielding parietes than the inferior ; they have less room for expansion; consequently, if there is any increase in the vascular current supplying these parts, the difference between the pressure of the parietes and of the atmosphere within the vesicles will increase unduly, and effusion will take place into the latter. In acute tuberculosis, we do not observe this peculiar election, because the process is of a moro active character; the strain upon the capillaries of the entire organ is greater than they can bear, and we consequently find the deposit takes place with much uniformity throughout the lung. In the chronic forms in which tubercular deposit generally occurs, the balance of the forces in the different parts of the vascular system is in a measure preserved, and only the very weak points are assailed. We do not at all deny that other forces come into play, and that there are elective affinities between different tissues and morbid products with which we are not even acquainted as yet; but it appears that the circumstance alluded to is one of considerable importance in its bearings upon tubercle, both in the lungs and in the brain and abdominal tissues. To take a single instance from the latter : in scrofulous deposit in the kidneys, where does the tubercular matter invariably present itself? In the loose textures of the cortical substance. The dense tubular tissue, with its stronger basement membrane and firmer epithelial coat, wards off the encroachment ; but the feebler texture of the convoluted tubes is unable to repel the enemy.

Allow me now finally to examine shortly the ultimate constituents of tubercular deposit, to see partly whether it exhibits characters by which we may surely recognise it, and partly whether it offers, as far as our present knowledge goes, such features as to destroy all fair ground for hope that we may succeed in curing or eradicating it from the system. Perhaps I ought to have apologised to you for the method which I have pursued in the consideration of the subject; but I have followed the same mode of explaining. to you my views, as I have followed in arriving at them myself. The ruder and more general characters of disease, and their relation to physiological states, are those which first attract our attention; from their examination we proceed to the contemplation of the more recondite phenomena of disease; and thus, by truthful observation and rigid inductive analysis, may hope to arrive at the real laws which govern the most wonderful fabric of the human body.

The simplest definition of tubercle appears to me to be, according to the present state of knowledge, the following : Tubercle is an exudation from the blood of a protein compound, incapable of organisation, but undergoing certain physical changes independent of vital influences. Tubercle is, in fact, effete matter which the powers of the system are unable to use as building material to repair the normal waste; and it is deposited in this or that organ of the body according as it is invited by the greater or less debility of the part. Tubercle is not a plastic material ; it is not a growth; it is not the manifestation of a depraved germin- 
ating power, superadded, ss it were, upon the normal energies of the system, or taking their place, such as we find to be the character of malignant disease; nor, on the other hand, is it identical with the effusions of blood-constituents which result from an exaltation of the normal energies, and continue in possession of their vitality, by which they are susceptible of organisation. This we do not see in tubercular deposit, which must be viewed as bearing to the diathesis giving rise to it, very nearly the same relation as, to use the strongest comparison that suggests itself to us, calculus in the bladder bears to the calculous diathesis to which it is due. There is, unfortunately, no such emunctory for the effete protein compounds, as there is for the excess of saline constituents of the blood; or tubercle might accumulate as the latter do, at a given point, and the product be removed by operative proceedings, or by chemical solution. The lungs and the skin have this duty to perform; but I need not stop to point out to you why we have not yet succeeded in destroying the tubercular product in the former, and removing it from them, by direct applications. I do not myself despair of a remedy being discovered which, in a gaseous form, may be conveyed to the deposit in the lungs, and, by dissolving it, enable the patient to expectorate it; but this would only affect a single organ. The cachexia leading to the local product will ever remain the real malady to deal with, so that we may anticipate its local effects.

The changes which take place in the deposit itself, and which have been the source of much discussion, and of some very wild speculations, are, as I have already ohserved, closely allied to what we see taking place out of the human body in inorganic substances. They seem to follow the laws regulating crystallization and chemical decomposition rather than those of vital action.

The earliest form in which tubercle presents itself to the eye is that of a faintly granular blastema, in which we are only just able to trace a tendency to aggregation into circular forms. An instance of this is given in the microscopic view of the miliary tubercle represented in drawing No. $91 a$, which was taken from a case of acute tuberculosis occurring in a patient of Dr. Markham's, secondary to rheumatic disease of the heart, and central softening of the brain. Here, as elsewhere, while the process of deposition continued, the vicinity of the tubercular matter was surrounded by exudation corpuscles, with or without an enveloping wall. The next form which we find tubercle presenting is that of more definite corpuscles; they offer an oval form, with a more or less sharp outline, and a granular surface. These corpuscles are surrounded by the granular blastema before mentioned, which now becomes more definitely marked, and by and bye appears to eliminate oil-globules in a greater or less quantity. The tubercular corpuscle does not present a nucleus as its normal constituent ; it is, in fact, regarded by some, among whom I may be allowed to mention your excellent secretary $D r . H$. Jones, as itself a nucleus. We occasionally find cells with nuclei in tubercular matter, as you will observe in several of the drawings which I send round, but I am inclined to think that they are generally, if not always, derived from the normal tissues of the organs in which the deposit has taken place. In many cases the corpuscles offer no distinct cell-wall, but appear merely to be an aggregation of the granular blastema; and at all times the envelope presents but a faint outline, compared to the sharp and well-marked margin which we discover in the cancer or epithelium cell. In examining tubercle taken from different organs, we must never forget that an admixture of the cells and corpuscles belonging to the healthy tissues may take place, which, at first sight, gives an appearance to the microscopic field different from that described. Another source of difficulty, also, consists in the admixture of the products of secondary inflammation, which is often excited by the tubercle acting as a foreign body. In the former case, our knowledge of the healthy tissues must guide us; in the latter, we must carefully discriminate blood-corpuscles, pus, or debris of the tissues, from the tubercular deposit. In the instance of tuberculated kidney which I submit, you will see that renal cells are mixed up with the true tubercular matter; in the glands the normal corpuscles often closely resemble the tubercular, and some care is necessary to distinguish the two. The characters which I have laid down will generally suffice to determine the question; and we may also bear in mind, that while in normal components there is generally more definiteness of outline and uniformity of shape and size, the elements of morbid products are characterised by an absence of that typical regularity. The dimension of the tubercular corpuscle generally fluctuates from one to three five-thousandths of an inch.

A term has of late been brought into rogue by the authority of great names, to which, before concluding this brief sketch, it is necessary that I should allude, as the subject to which it refers is closely associated with tubercular disease. I refer to fibrinous deposits. Many of the cases which are thus denominated present no differences perceptible, either to the naked eye or under the microscope, by which we can distinguish the product from tubercle; and in such it is scarcely in accordance with sound induction to assume a different disease, until we are able to domonstrate a distinct primary lesion in the blood. It is not my intention to enter fully into this very important question at present, because I should fear to exceed the limits of your patience; but I wish to point out that, while there is a wide distinction between the two forms of disease in their well marked characters, they occasionally merge into one another, and are associated together. In drawing 104, $I$ have represented the most marked instance of a combination of tubercle and fibrine which I have met with. You perceive that the characters of each are maintained as shown in the micruscopic view; while, at the same time, the naked eye appearance of the morbid product corresponds with those of ordinary tubercle. When we remember the close approach between the elementary composition of fibrine and albumen, it is only surprising that the morbid products which are formed from them should present on the whole the broad distinctions that we recognize. Here, as elsewhere, we must look further back than to the mere local deposit: the primary cause resides in the perverted impulse given to the system; that impulse itself we shall never be able to seize with physical means, but we may hope to obtain an insight, a sensual appreciation of its manifestations at an earlier period than has yet been vouchsafed to us. When we do this, we may hope to be more successful in applying our curative agents ; till then we shall see but as through a glass darkly, and our steps will be, like those of the infant learning to walk, insecure and infirm.

I cannot take my leave of you without apologising for attempting to touch upon a subject of such vast importance as that of tubercle in so cursory a manner. No one is more conscious than I am myself of the very imperfect manner in which the little that has been said has been brought before you. And though I may have failed to suggest anything which your own observations and researches have not already made out, I may succeed in eliciting the observations of other inquirers into this field of pathology, which will deserve the attention of the learned members of this Society.

May 1833.

\section{ON REVACCINATION.}

\section{By J. A. HINGESTON, Esq.}

Or those who hare been once properly vaccinated, an indeterminate number become again susceptible of raccination at a subsequent but indeterminate period of their lives. It is said that this susceptibility never occurs within six months after an effective primary vaccination; and this interval of protection has been extended to seren or even ten years ; but there are no proofs to warrant our implicit confidence in this assertion. The scar of a genuine vesicle is no evidence of insusceptibility ; for those without a scar will remain insusceptible both of the small-pox and revaccination all their days; while others, with a scar of 